\title{
Kireçtaşı Kökenli Kırma Kumdaki İnce Madde Oranının Beton Kıvamına ve Dayanımına Etkisi
}

\author{
The Effects of the Ratio of Fine Materials in Limestone Crushed Sand on Consistency and \\ Strength of Concrete
}

\author{
Fatih DEŞiKiK*1,a, illker USTABAȘ ${ }^{2, b}$ \\ ${ }^{I}$ DSI Coruh Projeleri 26. Bölge Müdürlüğ̈̈, Kalite Kontrol ve Laboratuvar Sube Müdürlüğ̈̈, 08000, Artvin \\ ${ }^{2}$ Recep Tayyip Erdoğan Üniversitesi, Mühendislik Fakültesi, İnşaat Mühendisliği Bölümü, 53000, Rize
}

• Geliş tarihi / Received: 02.06.2018 • • Düzeltilerek geliş tarihi / Received in revised form: 30.07.2018 • Kabul tarihi / Accepted: 04.09.2018

\begin{abstract}
$\ddot{O} z$
Bu çalışmada, kireçtaşı kökenli agrega içerisinde bulunan ince madde oranının beton kıvamına ve dayanımına olan etkileri araştııılmıştır. Çalışma kapsamında iki farklı grupta on beş tane beton tasarımı yapılmıştır. Birinci grupta 0.580.53-0.56 su/çimento oranına sahip, her farklı su/çimento oranından üçer tane olmak üzere dokuz adet beton üretilmiştir. İkinci gruptaki betonların ise çökmeleri eşit olacak şekilde su/çimento oranları ayarlanmıştır. Üretilen betonlarda kullanılan ince agreganın ASTM C 117'ye göre $0.075 \mathrm{~mm}$ elekten geçen kısmı $\% 5, \% 10$ ve $\% 15$ olmuştur. Bu çalışmada kullanılan agrega granülometrisine göre kil türü ince malzeme içermeyen kireçtaşı kökenli ince maddenin beton boşluklarında ince malzeme vazifesi görerek betonun çökme miktarını arttırdığı tespit edilmiştir. Çökmeler ve basınç dayanımları açısından değerlendiğinde betonda kullanılacak kireçtaşı kökenli ince agregada ince madde oranının $\% 15$ seviyesine kadar çıkarılabileceği belirlenmiştir.
\end{abstract}

Anahtar kelimeler: Beton, Çökme, İnce Madde, İşlenebilirlik, Kireçtaşı

\begin{abstract}
In this study, the effect of fine materials ratio in limestone aggregate to consistency and strength of concrete has been investigated. Within the scope of study, fifteen concrete designs were produced in three different groups. In the first group, 9 concrete mixtures which have 0.58-0.53-0.56 quantity of water/cement 3 for each were produced. In the second group, water/cement quantity of concrete mixtures were arranged to have the same slumps. The fine aggregate used in the concrete produced was 5\%, 10\% and 15\% of the area passing through the $0.075 \mathrm{~mm}$ sieve according to ASTM C 117. In this study according to aggregate granulometry, mineral filler which does not contain small material like clay raises quantity of concrete slump as small materials in concrete space. It is determined that in fine aggregate which is from limestone will used concrete, quantity of mineral filler can reach $15 \%$.
\end{abstract}

Keywords: Concrete, Slump, Mineral Filler, Workability, Limestone

\footnotetext{
*a Fatih DEŞiK; fatihdesik@gmail.com; Tel: (0466) 21212 77; orcid.org/0000-0001-5035-1894

${ }^{\mathrm{b}}$ orcid.org/0000-0003-0473-2543
} 


\section{Giriş}

Beton sektörü agrega temini için deniz veya nehir gibi doğal kaynakları kullanmaya devam etmektedir. Özellikle ince agrega doğal kaynaklardan temin edilmektedir ve çimento/beton üretimindeki artışa bağlı olarak doğal kaynaklar ince agrega temininde yetersiz kalmaktadır (Laserna ve Montero, 2016; Rashad, 2016). Ülkemizde özellikle Çoruh havzasından uzun yıllardan beri başta ince agrega olmak üzere agrega temin edilmektedir (Yildırım ve Tekin, 2014). Çoruh havzasında art arda inşa edilen barajlar nedeniyle doğal agrega kaynakları rezervuar altında kalmıştır. $\mathrm{Bu}$ nedenle, son yıllarda beton imalatlarında gerekli agregalar taş ocaklarından elde edilen kırma taşlarla sağlanmaktadır. Kırma taştaki ince madde oranı beton özelliklerini etkileyen bir unsur olup betondaki içeriğinin belli oranlarda olmas1 gerekmektedir (Ramyar vd., 1995; Ulusöz vd., 2004; Boğa vd., 2014). ASTM C 117 standard1 ince agregada $0.075 \mathrm{~mm}$ elekten geçen malzeme miktarının en fazla $\% 7$, iri agrega için ise en fazla $\% 1$ olabileceğini belirtmektedir. TS 706 EN 12620 standard $10.063 \mathrm{~mm}$ elekten geçen malzemeyi çok ince malzeme muhtevası olarak adlandırmış ve çok ince malzeme muhtevasını $\% 4$ olarak sınırlandırmıştır. Betonda ince agrega ile iri agrega karıştırılarak kullanıldığından ASTM C 117'ye göre taş unu miktarı ile TS 706 EN 12620 standardiyla belirtilen ince malzeme muhtevası birbirine çok yakın değerlerdedir.

$\mathrm{Bu}$ araştırmanın yapıldığı Artvin bölgesindeki beton santrallerinin ürettikleri betonlarda doğal kaynaktan üretilen ince agrega kullanmamakta, alternatif olarak ince madde oranı yüksek kırma kum kullanılmaktadır. Bu şekilde sadece kırma kum ile ürettikleri betonlarda, ince agrega miktarı düşük, bazen çok az bazen de çok fazla çökmenin olduğu (kayma çökmesi), pompalanması ve kalıba yerleştirilmesi zor olan ancak dayanımı uygun betonlarla sıkça karşılaşılmaktadır. İstenilen inceliğe sahip kırma kum elde edilmesinde teknik açıdan güçlükler yaşanmakta ve söz konusu ince agrega ekonomik olmamaktadır. Beton santrallerinin kırma kum üretiminden kaynaklanan ince madde yüzdesini istenilen düzeyde ayarlayabilecek yıkama ve eleme sistemleri yeterli düzeyde değildir. Bundan dolay1, bölgedeki beton santralleri kırma taştan elde edilen kumu yıkanmış kum ve yıkanmamış kum olmak üzere betonda belirli yüzdelerde karıştırarak beton üretmektedirler.

Betonda çok ince malzeme muhtevasının artması işlenebilirlik ve kıvam kaybı sorunlarına neden olabilmektedir. Kendiliğinden yerleşen beton gibi kıvamı yüksek betonlarda kireçtaşı filleri beton kıvaminın artırılması ve segregasyonun önlenmesinde önerilen maddeler arasında yer almaktadır (Benjeddou vd., 2017).

$\mathrm{Bu}$ çalışmada agreganın kökenine ve su emme değerine göre ince madde oranı yüksek agregalarla beton üretilebilirliği araştırılmıştır. Kireçtaşı kökenli ince agregadaki ince madde oranı ASTM standartlarında belirtilen $\% 7$ oranın iki katı olacak şekilde kullanılarak betonun kıvamını ve basınç dayanımını nasıl etkilediği incelenmiştir. Çalışma kapsamında yıkanmış ve yıkanmamış kumlardan oluşan karışımlarda 200 nolu $(0.075 \mathrm{~mm})$ elekten geçen malzeme miktarı $\% 5, \% 10$ ve $\% 15$ olan betonlar üretilmiştir. Üretilen betonların bir kısmında su miktarları sabit tutularak çökme miktarlarındaki değişim, bazılarında da çökme miktarları sabit tutularak $\mathrm{su} /$ çimento oranlarındaki değişim incelenmiş ve betonların basınç dayanımları kıyaslanmıştır.

\section{Deneysel Çalıșmalar}

\subsection{Kullanulan Malzemeler}

Çalışmada kullanılan CEM II A-M (P-LL) 42.5 R tipi çimentoya ait fiziksel ve mekanik özellikler Tablo 1'de ve çimentonun ana oksit element içeriği de Tablo 2'de verilmiştir.

Tablo 1. Çimentoya ait fiziksel ve mekanik özellikler

\begin{tabular}{|c|c|c|c|c|c|c|c|}
\hline $\begin{array}{c}\text { Yoğunluk } \\
\left(\mathrm{gr} / \mathrm{cm}^{3}\right)\end{array}$ & $\begin{array}{c}\text { Priz } \\
\text { başlangıç } \\
\text { süresi }(\mathrm{dk})\end{array}$ & $\begin{array}{c}\text { Priz bitiş } \\
\text { süresi } \\
(\mathrm{dk})\end{array}$ & $\begin{array}{c}\text { Hacim } \\
\text { genleşme } \\
(\mathrm{mm})\end{array}$ & $\begin{array}{c}\text { Su } \\
\text { ihtiyacı } \\
(\%)\end{array}$ & $\begin{array}{c}\text { Özgül } \\
\text { yüzey } \\
\left(\mathrm{cm}^{2} / \mathrm{gr}\right)\end{array}$ & $\begin{array}{c}\mathbf{9 0 / 4 5} \text { Mikron } \\
\text { elekte kalıntı } \\
(\%)\end{array}$ & $\begin{array}{c}2 / 28 \text { Günlük } \\
\text { basınç dayanımı } \\
(\mathrm{MPa})\end{array}$ \\
\hline 3.01 & 169 & 230 & 1.0 & 32.8 & 3934 & $0.0 / 3.0$ & $29.2 / 53.7$ \\
\hline
\end{tabular}


Tablo 2. Çimento ve kırma kumdaki ince maddenin ana oksit element içeriği

\begin{tabular}{|c|c|c|c|c|c|c|c|c|c|}
\hline Bileşik & $\begin{array}{c}\mathbf{C a O} \\
(\%)\end{array}$ & $\begin{array}{c}\mathbf{S i O}_{\mathbf{2}} \\
(\%)\end{array}$ & $\begin{array}{c}\mathbf{A l}_{2} \mathbf{O}_{\mathbf{3}} \\
(\%)\end{array}$ & $\begin{array}{c}\mathbf{K}_{2} \mathbf{O} \\
(\%)\end{array}$ & $\begin{array}{c}\mathbf{M g O} \\
(\%)\end{array}$ & $\begin{array}{c}\mathbf{F e}_{2} \mathbf{O}_{3} \\
(\%)\end{array}$ & $\begin{array}{c}\mathbf{T i O}_{2} \\
(\%)\end{array}$ & $\begin{array}{c}\mathbf{N a}_{2} \mathbf{O} \\
(\%)\end{array}$ & $\begin{array}{c}\mathbf{S O}_{3} \\
(\%)\end{array}$ \\
\hline Çimento & 56.00 & 23.03 & 6.88 & 1.44 & 1.25 & 4.46 & 0.00 & 0.60 & 2.83 \\
\hline İnce Madde & 69.53 & 13.78 & 13.80 & 0.30 & 0.51 & 1.24 & 0.24 & 0.00 & 0.00 \\
\hline
\end{tabular}

$\mathrm{Bu}$ çalışmada üretilen betonlarda kullanılan iri agregalar Deriner Barajı ve HES İnşaatında kullanılan agregalar olup, Artvin ili Merkez ilçesinde bulunan bir beton santralinden temin edilmiştir ve granit kökenlidir. İnce agregalar Ferhatlı Tüneli İnşaatında kullanılan Artvin ili Ardanuç ilçesindeki kırma-eleme tesisinden alınmış kireçtaşı kökenli agregadır. İnce agreganın ana oksit element içeriği Tablo 2'de sunulmuştur. İnce agregaya metilen mavisi deneyi yapılmış, kil türü ince malzeme içermediği ve taş unu olduğu gözlemlenmiş-tir. İri ve ince agregalara ait fiziksel özellikler Tablo 3'te verilmiştir. İri ve ince agregalara ASTM C 131 standardına göre tane büyüklüğü dağılımı yapılmış olup, agregaların granülometri eğrileri Şekil 1'de verilmiş̧tir.

Beton santrallerinde genellikle süper akışkanlaştırıcı kimyasal katkılar kullanıldığından beton karışımlarına dahil edilmiştir. Betonda Sikament FFN-100 süper akışkanlaştırıcı katkı çimento kütlesinin $\% 1.5$ oranında kullanılmış ve teknik özellikleri Tablo 4'de verilmiştir.

Tablo 3. Agregalara ait fiziksel özellikler

\begin{tabular}{|c|c|c|c|c|c|}
\hline $\begin{array}{c}\text { Agrega sınıfları } \\
(\mathrm{mm})\end{array}$ & $\begin{array}{c}\text { Bağıl yoğunluk } \\
\left(\mathrm{kg} / \mathrm{dm}^{3}\right)\end{array}$ & $\begin{array}{c}\text { Su emme } \\
(\%)\end{array}$ & $\begin{array}{c}\text { Ínce madde } \\
\text { oranı }(\%)\end{array}$ & $\begin{array}{c}\text { Incelik } \\
\text { modülü }\end{array}$ & $\begin{array}{c}\text { Metilen } \\
\text { mavisi }\end{array}$ \\
\hline İri Agrega (12-25) & 2.76 & 0.3 & 0.1 & - & - \\
\hline İi Agrega (5-12) & 2.76 & 0.4 & 0.8 & - & - \\
\hline Yıkanmış Kum (0-5) & 2.63 & 1.5 & 4.5 & 2.8 & - \\
\hline Y1kanmamış Kum (0-5) & 2.60 & 2.1 & 17.1 & 2.5 & 0.8 \\
\hline
\end{tabular}

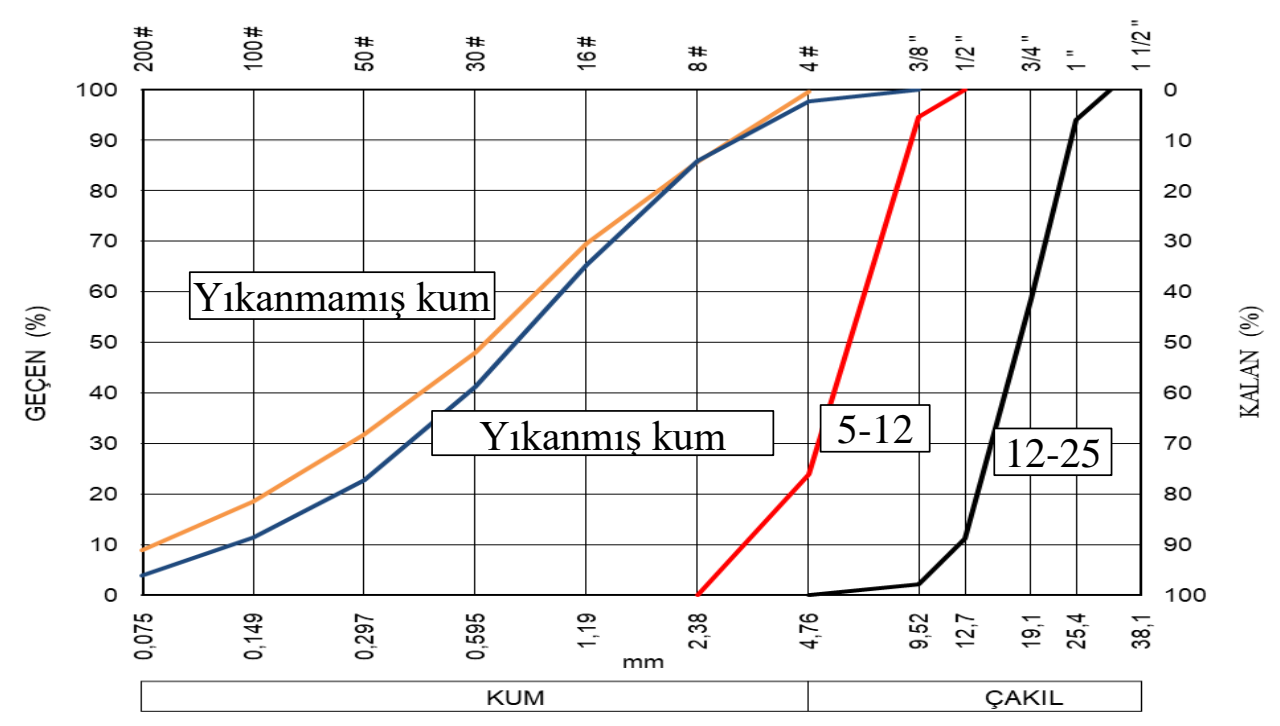

Şekil 1. Agregalara ait granülometri eğriler

Tablo 4. Kimyasal katkıya ait teknik özellikler

\begin{tabular}{|c|c|c|c|c|}
\hline Kimyasal yapı & $\begin{array}{c}\text { Yoğunluk } \\
(\mathrm{kg} / \mathrm{l})\end{array}$ & $\begin{array}{c}\text { PH } \\
\text { değeri }\end{array}$ & $\begin{array}{c}\text { Toplam klorür iyon } \\
\text { içeriği }(\%)\end{array}$ & $\begin{array}{c}\text { Dozaj kullanım } \\
\text { limitleri }(\%)\end{array}$ \\
\hline $\begin{array}{c}\text { Naftalin sülfonat } \\
\text { polimer esaslı sıv1 }\end{array}$ & 1.205 & 8 & 0.03 & $0.8-2.0$ \\
\hline
\end{tabular}




\subsection{Beton Tasarımlart ve Yapılan Deneyler}

Beton tasarımlarında $12-25 \mathrm{~mm}$ iri agregadan kütlece $\% 22$ ve $5-12 \mathrm{~mm}$ iri agregadan ise $\% 28$ oranında kullanılmıştır. Yıkanmış ve yıkanmamış kumun toplamı kütlece $\% 50$ olarak kullanılmış olup, yıkanmış kum ve yıkanmamış kumların kütlece yüzdeleri ince madde oranına göre değişkenlik göstermiştir. İnce agregadaki ince madde oranı Tablo 3'te görüldüğü gibi yıkanmış kumda \%4.5 ve yıkanmamış kumda \%17.1'dir. Dolayısıla ince agrega içerisinde bulunan ince madde oranın $\% 5, \% 10, \% 15$ olarak elde etmek için yıkanmış kum ve yıkanmamış kumdaki 0.075 $\mathrm{mm}$ elekten geçen miktarları ve beton tasarımlarındaki toplam karışım kum miktarı $\% 50$ 'ye göre oransal olarak hesaplanmıştır.

Böylece betondaki ince agregada ince madde oranı $\% 5$ olması için $\% 48$ oranında yıkanmış kum ile $\% 2$ oranında yıkanmamış kum, ince madde oranı \%10 olması için \%28.2 oranında y1kanmış kum ile \%21.8 oranında yıkanmamış kum, ince madde oranı \%15 olması için \%8.3 oranında yıkanmış kum ile \%41.7 oranında yıkanmamış kum karıştırılmıştır.

$\mathrm{Bu}$ betonlarda kullanılan maksimum agrega çapı $25.4 \mathrm{~mm}$ olan granülometri eğrisi Şekil 2, Şekil 3 ve Şekil 4 'te verilmiştir.

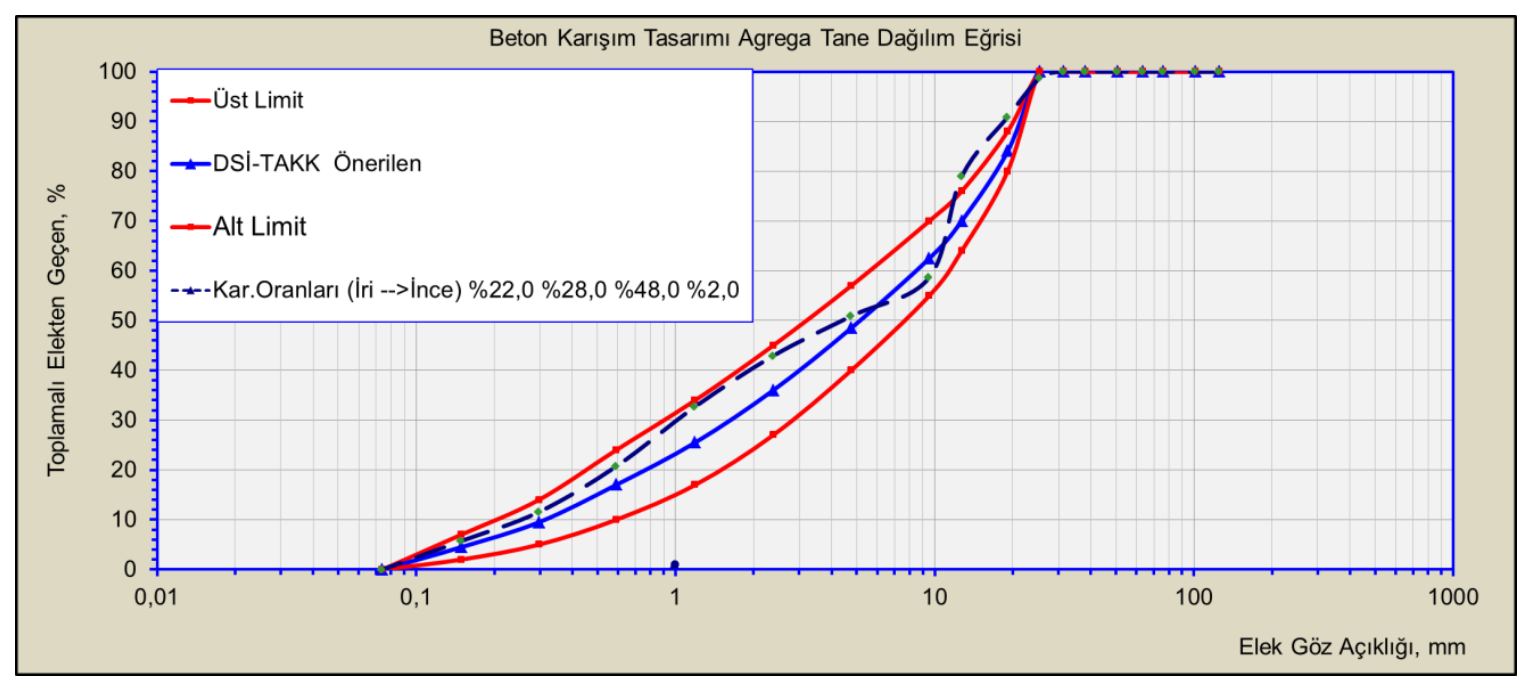

Şekil 2. İnce madde oranı \%5 olan karışımlar (Karışım No:A1-A4-A7-A9-A11-A14)

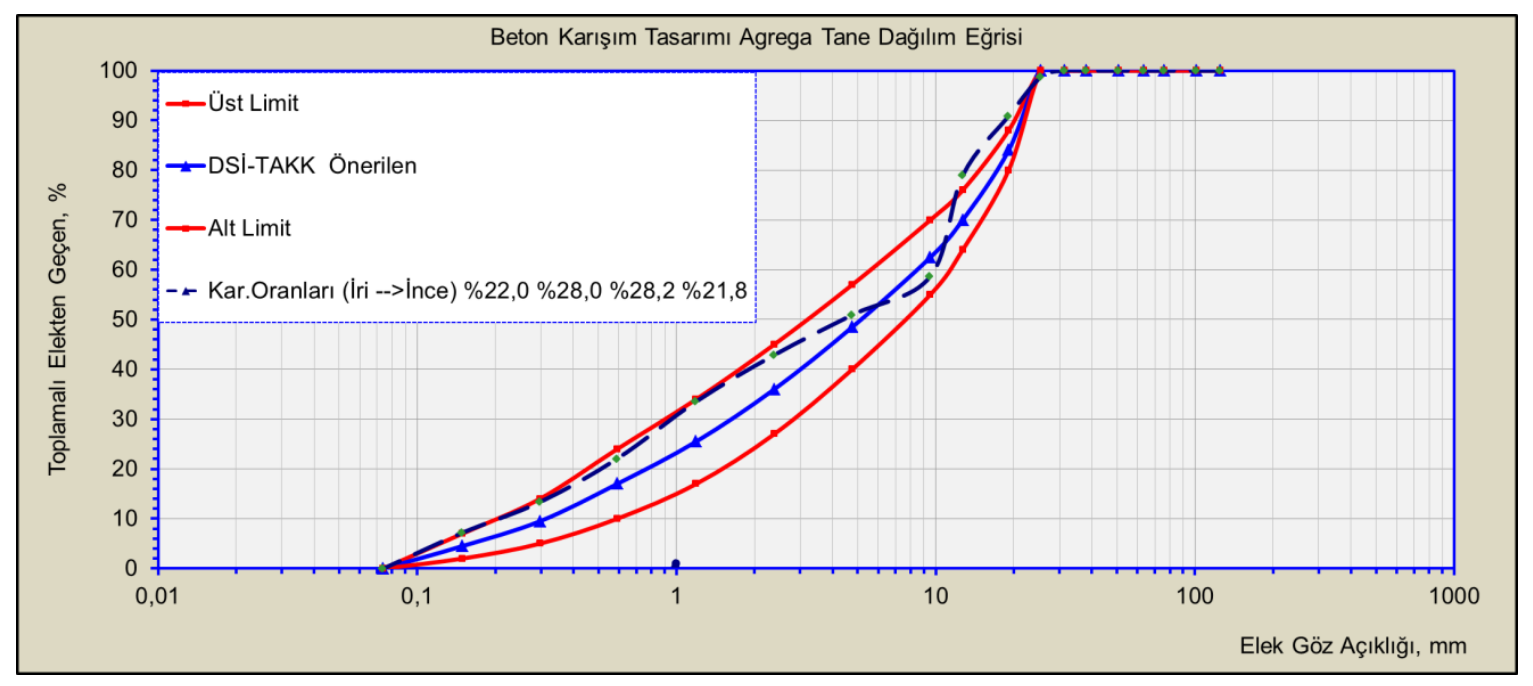

Şekil 3. İnce madde oranı \% 10 olan karışımlar (Karışım No:A2-A5-A12) 


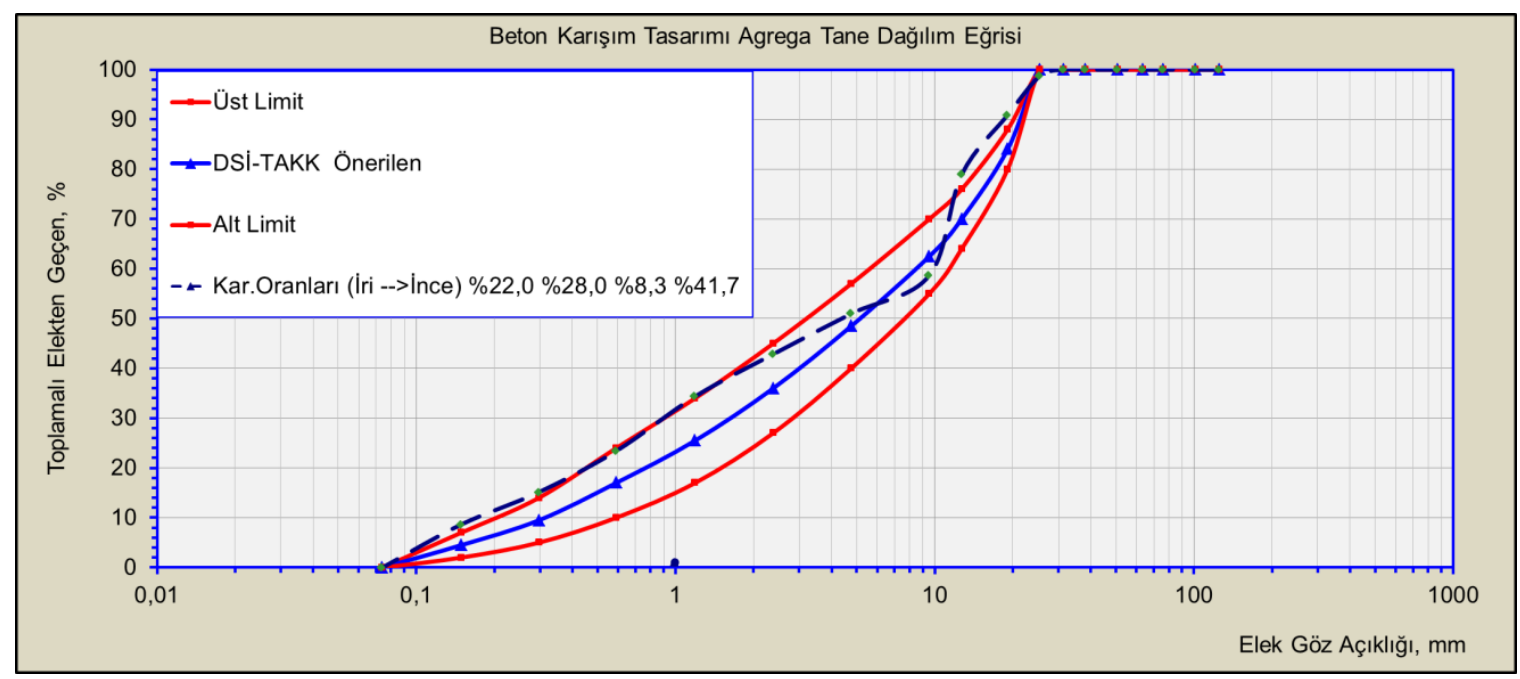

Şekil 4. İnce madde oran1 \%15 olan karışımlar (Karışım No:A3-A6-A8-A10-A13-A15)

Betonların tasarımında $1 \mathrm{~m}^{3}$ hacimdeki doygun kuru yüzeyde kullanılan malzemelerin kütleleri Tablo 5 ve Tablo 6'da verilmiştir. Tablo 5 ve Tablo 6'da belirtilen ince madde oranları yıkanmış ve y1kanmamış kumdan oluşan karışım kumunun $0.075 \mathrm{~mm}$ elekten geçen ince maddeyi temsil etmekte olup, ayrıca karışıma ince madde eklenmemiştir. Tablo 5'de görüldüğü üzere 1.grup 1. takımda 200 nolu elekten geçen malzeme miktarı \%5, \%10 ve \%15 olan karışımların taze betonda su miktarları sabit tutularak, çökme miktarındaki değişimler karşılaştırılmış ve doğruluğunu kanıtlamak için farklı çimento dozajında su miktarı sabit tutularak, 2. takım ve 3. takım için tekrar çökme miktarındaki değişimler kıyaslanmıştır. Tablo 6'daki 2.grup 1. takımda ise 200 nolu elekten geçen malzeme miktarı \%5, \%10 ve $\% 15$ olan karışımların çökme miktarı sabit tutularak su/çimento oranları kıyas edilmiştir. Yine bu grupta da doğruluğunu kanttlamak için farklı çimento dozajında çökme miktarı sabit tutularak, 2. takım ve 3. takım için tekrar $\mathrm{su} /$ çimento miktarındaki değişimler incelenmiştir.

Tablo 5. 1. grup betonlarda kullanılan malzeme miktarlar1

\begin{tabular}{|c|c|c|c|c|c|c|c|c|c|c|}
\hline $\begin{array}{c}\text { Karışım } \\
\text { no }\end{array}$ & $\begin{array}{c}\text { Takım } \\
\text { no }\end{array}$ & $\begin{array}{c}\text { İnce madde } \\
\text { oranı }(\%)\end{array}$ & $\begin{array}{c}\text { Çimento } \\
\text { dozajı } \\
(\mathrm{kg}) \\
\end{array}$ & $\begin{array}{c}\text { Su } \\
(\mathrm{kg})\end{array}$ & $\mathrm{S} / \mathrm{C}$ & $\begin{array}{c}\text { K. katkı } \\
(\mathrm{kg})\end{array}$ & $\begin{array}{c}\text { İri agrega } \\
\text { 12-25 mm } \\
(\mathrm{kg}) \\
\end{array}$ & $\begin{array}{c}\text { İri agrega } \\
5-12 \mathbf{~ m m} \\
(\mathrm{kg})\end{array}$ & $\begin{array}{c}\text { Yıkanmış } \\
\text { kum 0-5 mm } \\
(\mathrm{kg}) \\
\end{array}$ & $\begin{array}{c}\text { Yıkanmamış } \\
\text { kum 0-5 mm } \\
(\mathrm{kg})\end{array}$ \\
\hline A1 & \multirow{3}{*}{1} & 5 & 300 & 175 & 0.58 & 4.5 & 415.0 & 528.2 & 905.6 & 37.7 \\
\hline A2 & & 10 & 300 & 175 & 0.58 & 4.5 & 414.1 & 527.0 & 530.8 & 410.3 \\
\hline A3 & & 15 & 300 & 175 & 0.58 & 4.5 & 413.1 & 525.8 & 155.9 & 783.0 \\
\hline A4 & \multirow{3}{*}{2} & 5 & 325 & 173 & 0.53 & 4.9 & 411.1 & 523.2 & 896.9 & 37.3 \\
\hline A5 & & 10 & 325 & 173 & 0.53 & 4.9 & 410.1 & 522.0 & 525.7 & 406.4 \\
\hline A6 & & 15 & 325 & 173 & 0.53 & 4,9 & 409.2 & 520.8 & 154.4 & 775.5 \\
\hline A11 & \multirow{3}{*}{3} & 5 & 325 & 183 & 0.56 & 4.9 & 405.2 & 515.6 & 884.0 & 36.8 \\
\hline A12 & & 10 & 325 & 183 & 0.56 & 4.9 & 404.2 & 514.4 & 518.1 & 400.5 \\
\hline A13 & & 15 & 325 & 183 & 0.56 & 4.9 & 403.2 & 513.2 & 152.1 & 764.3 \\
\hline
\end{tabular}

Çalıșma kapsamında her beton karıșımından $80 \mathrm{dm}^{3}$ beton üretilmiş olup, beton basınç dayanımı testi için 12 adet $(15 \times 15 \times 15) \mathrm{cm}$ ebatlarında numuneler alınmıştır. Söz konusu beton karışımlardan taze betonda slump, yoğunluk ve hava miktarı tayini deneyi yapılmıştır. Taze betonda hava miktarının tayini ise TS EN 12350-7 standardı içerisinde yer alan basınç ölçme metoduna göre yapılmıştır. 
Tablo 6. 2. grup betonlarda kullanılan malzeme miktarları

\begin{tabular}{|c|c|c|c|c|c|c|c|c|c|c|}
\hline $\begin{array}{c}\text { Karışım } \\
\text { no }\end{array}$ & $\begin{array}{c}\text { Takım } \\
\text { no }\end{array}$ & $\begin{array}{c}\text { İnce madde } \\
\text { oranı }(\%)\end{array}$ & $\begin{array}{c}\text { Çimento } \\
\text { dozajı } \\
(\mathrm{kg})\end{array}$ & $\begin{array}{c}\mathrm{Su} \\
(\mathrm{kg})\end{array}$ & $\mathbf{S} / \mathbf{C}$ & $\begin{array}{c}\text { K. katkı } \\
(\mathrm{kg})\end{array}$ & $\begin{array}{c}\text { İri agrega } \\
12-25 \mathrm{~mm} \\
(\mathrm{~kg})\end{array}$ & $\begin{array}{c}\text { İri agrega } \\
5-12 ~ \mathbf{~ m m} \\
(\mathrm{kg})\end{array}$ & $\begin{array}{c}\text { Yıkanmış } \\
\text { kum 0-5 mm } \\
(\mathrm{kg})\end{array}$ & $\begin{array}{c}\text { Yıkanmamış } \\
\text { kum 0-5 mm } \\
(\mathrm{kg}) \\
\end{array}$ \\
\hline A7 & \multirow{3}{*}{1} & 5 & 300 & 181 & 0.60 & 4.5 & 411.5 & 523.7 & 897.8 & 37.4 \\
\hline A2 & & 10 & 300 & 175 & 0.58 & 4.5 & 414.1 & 527.0 & 530.8 & 410.3 \\
\hline A8 & & 15 & 300 & 169 & 0.56 & 4.5 & 416.7 & 530.3 & 157.2 & 789.7 \\
\hline A9 & \multirow{3}{*}{2} & 5 & 325 & 183 & 0.56 & 4.9 & 405.2 & 515.6 & 884.0 & 36.8 \\
\hline A5 & & 10 & 325 & 173 & 0.53 & 4.9 & 410.1 & 522.0 & 525.7 & 406.4 \\
\hline A10 & & 15 & 325 & 167 & 0.51 & 4.9 & 412.7 & 525.2 & 155.7 & 782.2 \\
\hline A14 & \multirow{3}{*}{3} & 5 & 325 & 193 & 0.59 & 4.9 & 399.2 & 508.1 & 871.0 & 36.3 \\
\hline A12 & & 10 & 325 & 183 & 0.56 & 4.9 & 404.2 & 514.4 & 518.1 & 400.5 \\
\hline A15 & & 15 & 325 & 174 & 0.54 & 4.9 & 408.6 & 520.0 & 154.1 & 774.4 \\
\hline
\end{tabular}

\section{Bulgular ve Tartışma}

Tablo 7'deki betonların çimento dozajları farklı olan üç takımda da ince madde oranı $(0.075 \mathrm{~mm}$ elekten geçen ince malzeme) arttıkça çökme miktarlarının arttığı, betonlardaki hava miktarının azaldığı görülmektedir. Şekil 5a (karıșım no: A1)'da yapılan çökme deneyinde kayma çökmesinin oluştuğu görülmektedir. $\mathrm{Bu}$ tür çökme, iri agrega ve ince agrega karışım oranı iyi ayarlanmamış ve iri agrega miktarı fazla olan betonlarda görülmektedir. Şekil 5b (karışım no: A2)'de ise beton çökmesinin Şekil 5a'daki görsele göre daha homojen olarak çöktüğü görülmektedir. Şekil 5c (karışım no: A3) görselinde ise beton çökmesinin üst kısmında eşit miktarda homojen (hakiki çökme) şekilde olduğu görülmektedir.
Kullanılan agregadaki ince madde oranı arttıça betonlardaki kayma çökmesi hakiki çökmeye dönmüştür.

Şekil 6a (karışım no: A4)'daki görselde hakiki çökme meydana gelmiştir. Bu betonda çimento miktarının artması ve su miktarının azalması hakiki çökmenin oluşmasına neden olmuştur. Aynı görselde taze betonun üst kısmı kayma çökmesi yapacak şekilde eğilmiş ancak Şekil 5a'daki betona göre su miktarının azlığı ve çimento miktarının fazlalığından dolayı betonun üst kısmında devrilme olmamıştır. Şekil $6 \mathrm{~b}$ (karışım no: A5) ve Şekil 6c (karışım no: A6) betonları da Şekil 5b ve Şekil 5c'de verilen takım betonlarıyla aynı davranışı sergilemiştir.

Tablo 7. 1. grup betonlarda taze beton deney sonuçları

\begin{tabular}{|c|c|c|c|c|c|c|c|c|c|}
\hline $\begin{array}{c}\text { Karışım } \\
\text { no }\end{array}$ & $\begin{array}{c}\text { Takım } \\
\text { no }\end{array}$ & $\begin{array}{c}\text { İnce madde } \\
\text { oranı } \\
(\%) \\
\end{array}$ & $\mathbf{S} / \mathbf{C}$ & $\begin{array}{c}\text { Hava } \\
\text { sıcaklığı } \\
\left({ }^{\circ} \mathrm{C}\right)\end{array}$ & $\begin{array}{c}\text { Beton } \\
\text { sicaklığı } \\
\left({ }^{\circ} \mathrm{C}\right)\end{array}$ & $\begin{array}{l}\text { Çökme } \\
\text { /sınıfı } \\
(\mathrm{cm}) \\
\end{array}$ & $\begin{array}{c}\text { Çökme 30.dk } \\
\text { /sınıfı } \\
\text { (cm) }\end{array}$ & $\underset{\left(\mathrm{kg} / \mathrm{m}^{3}\right)}{\text { Yoğunluk }}$ & $\begin{array}{c}\text { Hava } \\
(\%)\end{array}$ \\
\hline A1 & \multirow{3}{*}{1} & 5 & 0.58 & 21 & 18 & $12 / \mathrm{S} 3$ & $3 / \mathrm{S} 1$ & 2390 & 1.7 \\
\hline $\mathrm{A} 2$ & & 10 & 0.58 & 16 & 19 & $15 / \mathrm{S} 3$ & $6 / \mathrm{S} 2$ & 2400 & 1.5 \\
\hline A3 & & 15 & 0.58 & 22 & 18 & $18 / \mathrm{S} 4$ & $9 / \mathrm{S} 2$ & 2410 & 1.3 \\
\hline A4 & \multirow{3}{*}{2} & 5 & 0.53 & 21 & 20 & $8 / \mathrm{S} 2$ & $0 / \mathrm{S} 1$ & 2400 & 2.0 \\
\hline A5 & & 10 & 0.53 & 21 & 19 & $15 / \mathrm{S} 3$ & $6 / S 2$ & 2410 & 1.5 \\
\hline A6 & & 15 & 0.53 & 21 & 19 & $17 / \mathrm{S} 4$ & $8 / \mathrm{S} 2$ & 2420 & 1.4 \\
\hline A11 & \multirow{3}{*}{3} & 5 & 0.56 & 35 & 31 & $14 / \mathrm{S} 3$ & $5 / \mathrm{S} 2$ & 2390 & 1.5 \\
\hline A12 & & 10 & 0.56 & 33 & 30 & $17 / \mathrm{S} 4$ & $8 / \mathrm{S} 2$ & 2410 & 1.4 \\
\hline A13 & & 15 & 0.56 & 35 & 30 & $19 / \mathrm{S} 4$ & $9 / \mathrm{S} 2$ & 2420 & 1.3 \\
\hline
\end{tabular}
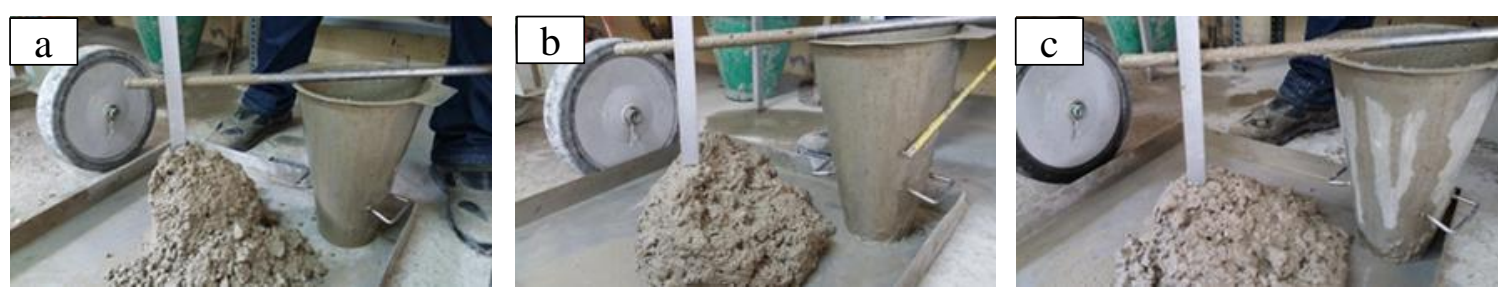

Şekil 5. 1. grup-1.takım betonlarına ait çökme deneyi görselleri 

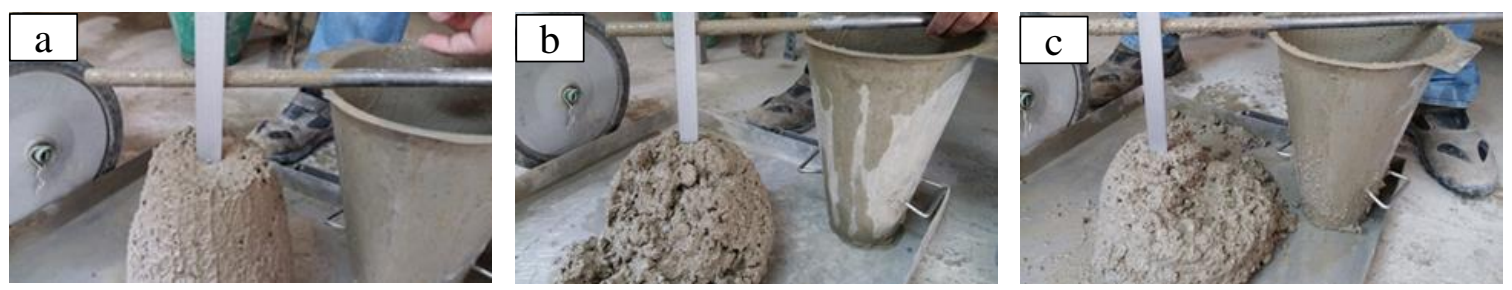

Şekil 6. 1. grup-2.takım betonlarına ait çökme deneyi görselleri

Şekil 7'deki görseller incelendiğinde Şekil 5 ve Şekil 6'daki benzer durumlara rastlanılmıştır. Şekil 5, Şekil 6 ve Şekil 7'de görüldüğü gibi betonlardaki ince madde oranının artması çökme miktarını arttırmıştır. Betonda ince madde oranı arttıkça betonun çökme miktarının düşmesi beklenmektedir. Ancak Şekil 5a, Şekil 6a ve Şekil 7a (karışım no: A11)'daki görsellerde verilen betonlarda kayma çökmesi meydana gelmiştir. Şekil 5c, Şekil 6c ve Şekil 7c (karışım no: A13)'deki betonlarda homojen şekilde hakiki çökme gerçekleştiği görülmektedir. İnce madde oranının artması beton agregasındaki boșlukları doldurmasından dolayı kayma çökmesi yerine hakiki çökme oluşmasına neden olmuştur. Yıkanmış kum ve yıkanmamış kumun su emme değerleri arasında çok fark olmadığından dolayı ince madde oranı arttıkça resimlerde olduğu gibi çökme miktarı artmıştır.

Tablo 8'de görüldügü üzere ince madde oranı arttıkça üç farklı takımda da aynı çökmede betonun su/çimento oranı 0.60 'dan 0.56 'ya, 0.56 'dan 051 'e ve 0.59 'dan 0.54 'e düşmüştür.
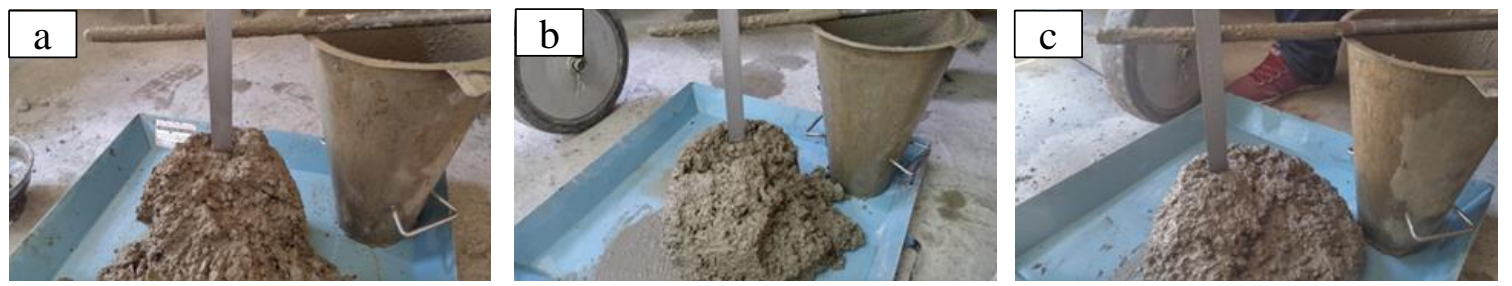

Şekil 7. 1. grup-3.takım betonlarına ait çökme deneyi görselleri

Tablo 8. 2. grup betonlarda taze beton deney sonuçları

\begin{tabular}{|c|c|c|c|c|c|c|c|c|c|}
\hline $\begin{array}{c}\text { Karışım } \\
\text { no }\end{array}$ & $\begin{array}{c}\text { Takım } \\
\text { no }\end{array}$ & $\begin{array}{c}\text { İnce madde } \\
\text { oranı }(\%)\end{array}$ & $\mathrm{S} / \mathrm{C}$ & $\begin{array}{c}\text { Hava } \\
\text { sicaklı̆g }\left({ }^{\circ} \mathrm{C}\right) \\
\end{array}$ & $\begin{array}{c}\text { Beton } \\
\text { sicaklığ }\left({ }^{\circ} \mathrm{C}\right) \\
\end{array}$ & $\begin{array}{c}\text { Ç̈̈kme/ } \\
\text { sinff }(\mathrm{cm})\end{array}$ & $\begin{array}{c}\text { Ç̈̈kme 30.dk } \\
\text { /sınıfi (cm) } \\
\end{array}$ & $\begin{array}{c}\begin{array}{c}\text { Yoğunluk } \\
\left(\mathrm{kg} / \mathrm{m}^{3}\right)\end{array} \\
\end{array}$ & $\begin{array}{c}\text { Hava } \\
(\%)\end{array}$ \\
\hline A7 & \multirow{3}{*}{1} & 5 & 0.60 & 19 & 19 & $15 / \mathrm{S} 3$ & $5 / \mathrm{S} 2$ & 2400 & 1.6 \\
\hline A2 & & 10 & 0.58 & 16 & 19 & $15 / \mathrm{S} 3$ & $6 / \mathrm{S} 2$ & 2410 & 1.5 \\
\hline A8 & & 15 & 0.56 & 20 & 19 & $15 / \mathrm{S} 3$ & $5 / \mathrm{S} 2$ & 2430 & 1.4 \\
\hline A9 & \multirow{3}{*}{2} & 5 & 0.56 & 15 & 19 & $15 / \mathrm{S} 3$ & $5 / \mathrm{S} 2$ & 2410 & 1.7 \\
\hline A5 & & 10 & 0.53 & 21 & 19 & $15 / \mathrm{S} 3$ & $6 / \mathrm{S} 2$ & 2420 & 1.5 \\
\hline A10 & & 15 & 0.51 & 15 & 19 & $15 / \mathrm{S} 3$ & $5 / \mathrm{S} 2$ & 2430 & 1.4 \\
\hline A14 & \multirow{3}{*}{3} & 5 & 0.59 & 35 & 30 & $17 / S 4$ & $7 / \mathrm{S} 2$ & 2390 & 1.6 \\
\hline A12 & & 10 & 0.56 & 33 & 30 & $17 / \mathrm{S} 4$ & $8 / \mathrm{S} 2$ & 2410 & 1.4 \\
\hline A15 & & 15 & 0.54 & 34 & 30 & $17 / \mathrm{S} 4$ & $7 / \mathrm{S} 2$ & 2430 & 1.2 \\
\hline
\end{tabular}

Şekil 8, Şekil 9 ve Şekil 10'da çökme miktarları eşit ayarlanmış betonlar görülmektedir. Çökme miktarlarını eşit ayarlamak için karışım yapılırken su ekleme çıkarma yapılmamış ve deneme yanılma yoluyla çökme miktarları eşit olarak ayarlanmıştır. İnce madde oranı $\% 5, \% 10$ ve $\% 15$ olan karışımların resimlerde görüldüğü üzere çökmeler sabit tutulduğunda, karışım içerisindeki ince madde oranı attırarak aynı çökmeyi elde etmek için Tablo 8'de görüldüğü gibi daha az su kullanılmıştır. Tablo 8'de belirtilen çökme miktarları TS EN 206-1 standardına göre sinıflandırılmıştır. TS EN 206-1 standardına göre 1. ve 2 . takım için başlangıç çökmesi $10-15 \mathrm{~cm}$ olan S3 sınıfindan $30 \mathrm{dk}$ sonraki çökme değeri 5-9 $\mathrm{cm}$ arasında olan S2 sınıfına geçmiştir. Bu durum 
3. takımda ise başlangıç çökmesi $16-21 \mathrm{~cm}$ olan S4 sinıfindan $30 \mathrm{dk}$ sonraki çökme değeri $5-9 \mathrm{~cm}$ arasında olan S2 sınıfına geçmiştir. Beton agregasındaki ince madde oran $1 \% 5, \% 10$ ve $\% 15$ olan karışımlarda 30 dakika sonraki çökme kayıpları birbirine yakın olduğu gözlemlenmiştir. $\mathrm{Bu}$ durum yıkanmış kum ve yıkanmamış kumun su emme değerleri arasında çok fark olmayışından kaynaklanmıştır. Eğer su emme değerleri arasındaki fark çok fazla olsaydı ince madde oranı arttıkça çökme kaybı artabilirdi. Ramyar vd. (1995) yapmış olduğu çalışmada taş unu artışıyla beton çökmelerinde azalmanın olduğunu tespit etmiştir. Ayrıca \%15 miktarında taş unu kullanımında çökmelerdeki azalmanın belirgin olmadığını belirtmişlerdir. Benjendou vd. (2017) ürettikleri kendiliğinden yerleşen betonlarda kireçtaşı filleri kullanmaları betonlarının yayılma çaplarını artırdığını ve kireçtaşı fillerinin kendiliğinden yerleşen betonlarda kıvamı artırıcı yönde etkisi olduğunu belirtmişlerdir. $\mathrm{Bu}$ çalışmada beton agregasındaki iri malzeme ve ince malzeme karışım oranına göre kireçtaşı fillerinin betonun çökmesini artırabileceği tespit edilmiştir.
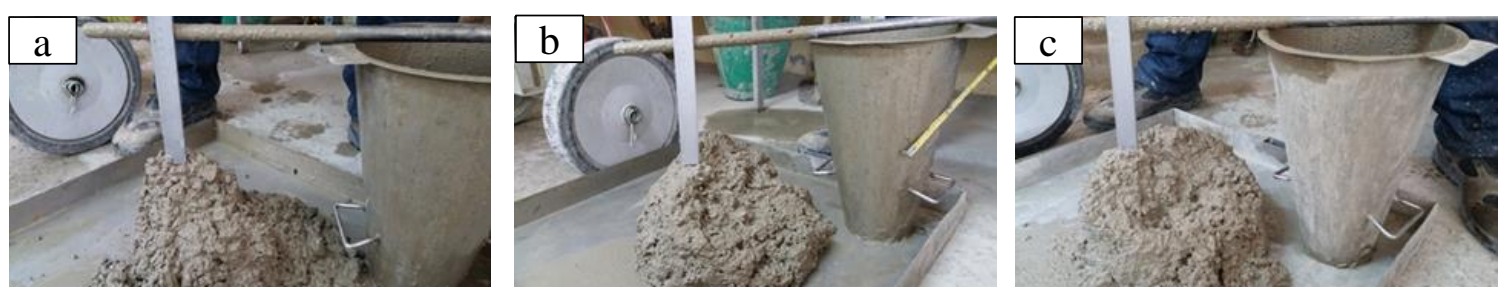

Şekil 8. 2. grup-1.takım betonlarına ait çökme deneyi görselleri
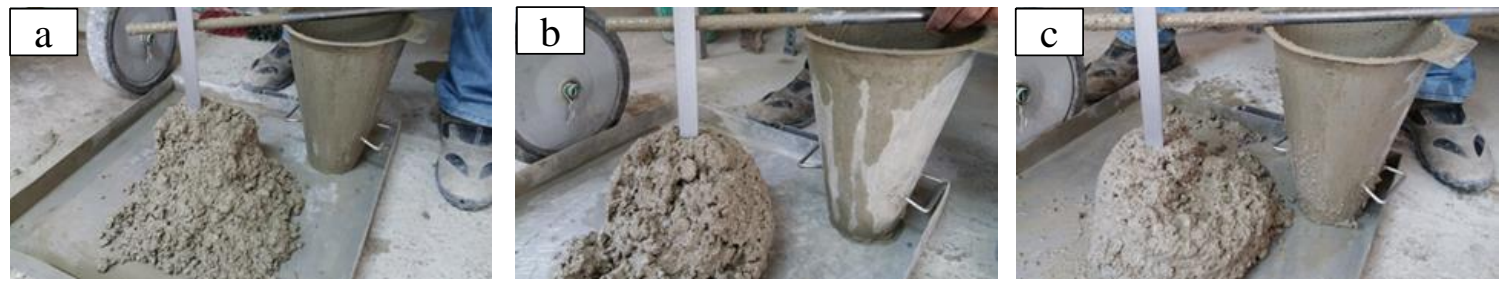

Şekil 9. 2. grup-2.takım betonlarına ait çökme deneyi görselleri
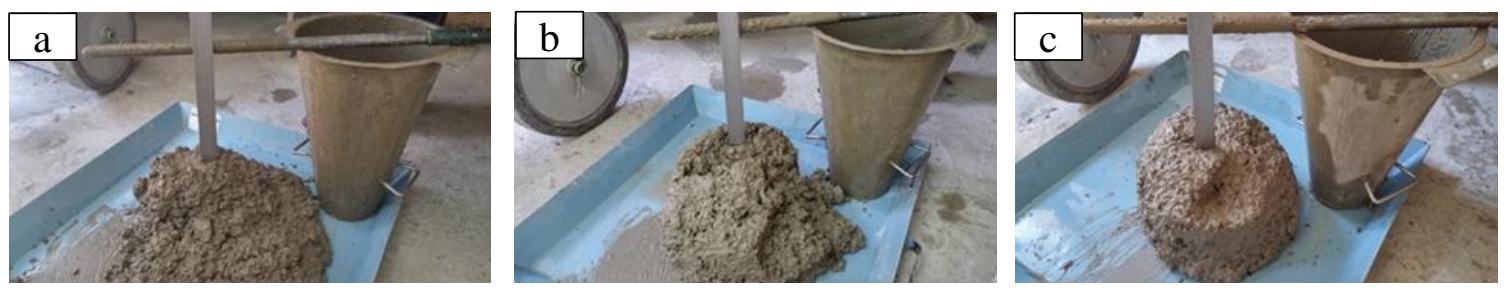

Şekil 10. 2. grup-3.takım betonlarına ait çökme deneyi görselleri

Böylelikle, 1. grupta görüldüğü üzere karışımların su miktarları sabit tutulunca ince madde oranı artarak çökme miktarı artmıştır. 2. grupta da çökme miktarları sabit tutulduğunda, ince madde oranı artması durumunda aynı çökme miktarını elde etmek için daha az su kullanılmaktadır. Özgül yüzey artmasına rağmen, betonun içindeki boşlukları ince madde doldurduğundan betonun işlenebilirliği artmış ve ince madde oranı arttıkça betonun daha az suya ihtiyaç duyduğu tespit edilmiştir. Böylece, 1. grup ve 2. grup beton karışımları birbirleriyle örtüşmektedir.

Şekil 11'de su/çimento oranları sabit tutulan 1. grup betonlarda ince madde oranı arttıkça beton basınç dayanımının azaldığı görülmektedir. Fakat, beton basınç dayanım gelişmelerinde ince malzemenin olumsuz bir etkisinin olduğu gözlemlenmemiştir. Boğa vd. (2014) atık mermer tozu katkılı kendiliğinden yerleşen betonların taze ve mekanik özelliklerinin incelenmesine yönelik yapmış olduğu çalışmada benzer sonuçlara rastlamıştır. $\mathrm{Bu}$ çalışmadaki ince maddenin kimyasal yapısı Boğa vd. (2014)'nin çalışmada kullandıkları malzeme ile benzer kimyasal bileşime sahiptir. Mermer tozu kullanılarak üretilen betonlarda dayanım açısından olumsuz bir etkisinin olmadığı belirtilmektedir. Özgan (2005) tarafından yapılan çalışmada ise su emme oranı $\% 5$ olan taş ununun $\% 15$ oranında kullanılmasının 
beton basınç dayanımını düşürdüğü ifade edilmiştir. $\mathrm{Bu}$ çalışmadaki 1.grup betonların basınç dayanımları ince madde oranının artmasıyla azalmıştır. Şekil 11'de verilen basınç dayanımlarındaki azalma miktarlarının fazla olmadığı görülmektedir. Beton çökmesindeki artış ve kırma kumdaki ince malzemenin uzaklaştırıl- masında karşılaşılacak ekonomi düşünüldüğünde ince agregadaki ince madde oranının $\% 5$ olabileceği, gerektiğinde bu oranın $\% 15^{\prime} \mathrm{e}$ çıkarılabileceği bu çalışmada tespit edilmiştir. $\mathrm{Bu}$ oran TS 706 EN 12620 standardına göre yüksek, ASTM C 117 standardına göre yaklaşık iki katına denk gelmektedir.
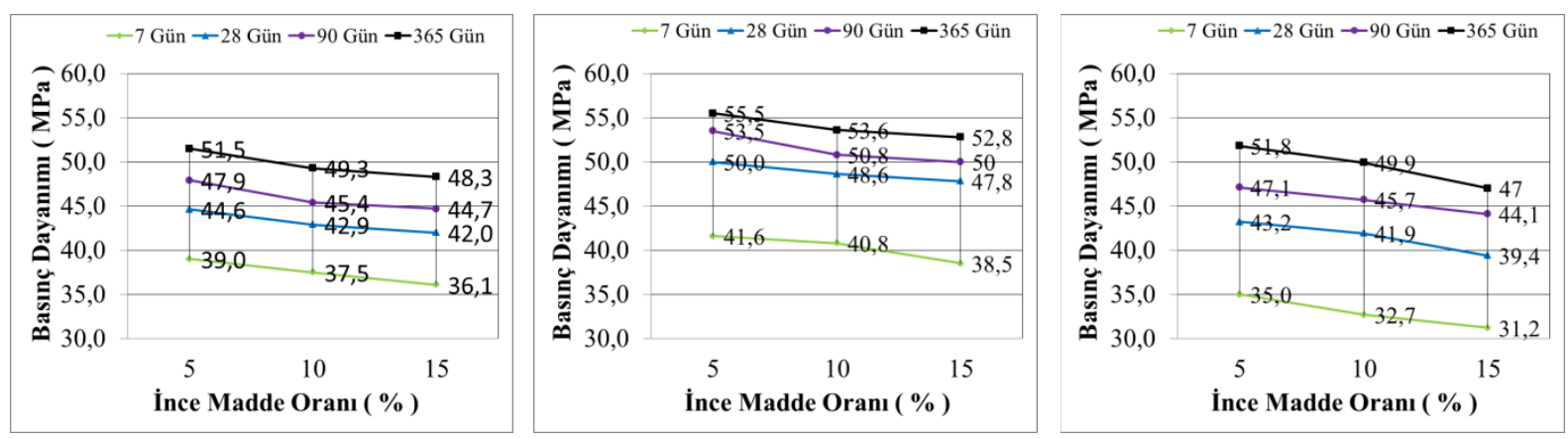

Şekil 11. 1.grup 1.takım, 2. takım ve 3. takım betonlardaki basınç dayanımı değişimleri

Şekil 12 de 2. grup betonlardaki basınç dayanımı değişimleri görülmektedir. 2. grup betonlarda ince madde oranı arttıkça aynı çökmeyi elde etmek için su miktarını azaltmak betonun dayanımının artmasına katkıda bulunmuştur. Aynı zamanda numunelere 90 günlük ve 365 günlük basınç dayanımı deneyi uygulanmıştır. Söz konusu ilerleyen yaşlardaki beton mukuvametleri Şekil 11 ve Şekil 12'de görüldüğü üzere, 7 günlük ve 28 günlük basınç dayanımından sonra artmaya devam etmiştir. Gülan ve Yıldız (2016) atık mermer tozu ve cam lif katkı1 betonun mekanik ve fiziksel özellikleri üzerine karbonatlaşmanın etkisi ile ilgili yapmış oldukları çalışmada mermer tozu arttıkça betonların boşluklarını doldurduğu ve basınç dayanımını arttırdığını saptamışlardır. Betonlarda sadece doğal kaynaktan sağlanan ince agrega kullanılırsa iri ve ince agrega dengesi sağlanamamaktadır. Özellikle $0.5 \mathrm{~mm}$ göz açıklıktan geçen agrega miktarı az olmaktadır. Kırma taşın inceliğinin daha çok azaltılması durumunda ince madde oranı yüksek ince agregalar elde edilmektedir. Uygulamada bu sorunun çözülmesi için doğal kaynaklardan sağlanan ince agrega ile kırma taş ince agrega karıştırılmaktadır. Doğal kaynaktan sağlanan ince agreganın temininde sorun yaşandığında ince malzeme miktarı az agregalarla beton üretilmektedir ve bu betonlarda dayanım sorunu olmasa bile betonun pompalanmasında ve kalıbına yerleştirilmesinde sorunlar yaşanmaktadır. $\mathrm{Bu}$ çalışmada kullanılan kireçtaşı kökenli ince agregada ince madde oranının artması betonun çökme değerinin yükselmesine neden olmuş ve aynı kıvamda daha düşük su/çimento oranıyla beton üretilmesine imkân sağlamıştır. Su/çimento oranı düşen betonlarda basınç dayanımının artması sağlanmıştır. Çobanoğlu vd. (2014) Denizli bölgesi traverten atıklarının beton agregası olarak kullanılabilirliğinin incelenmesine yönelik çalışmada ince agregada bulunan çok ince madde oran $\% 10$ - \%15 değerler arasinda olduğu ve beton agregası olarak kullanılabileceği değerlendirilmiştir. Bu çalışmadaysa ince madde oran $\% 15$ olan ince agrega ile de beton üretilebileceği görülmüştür.
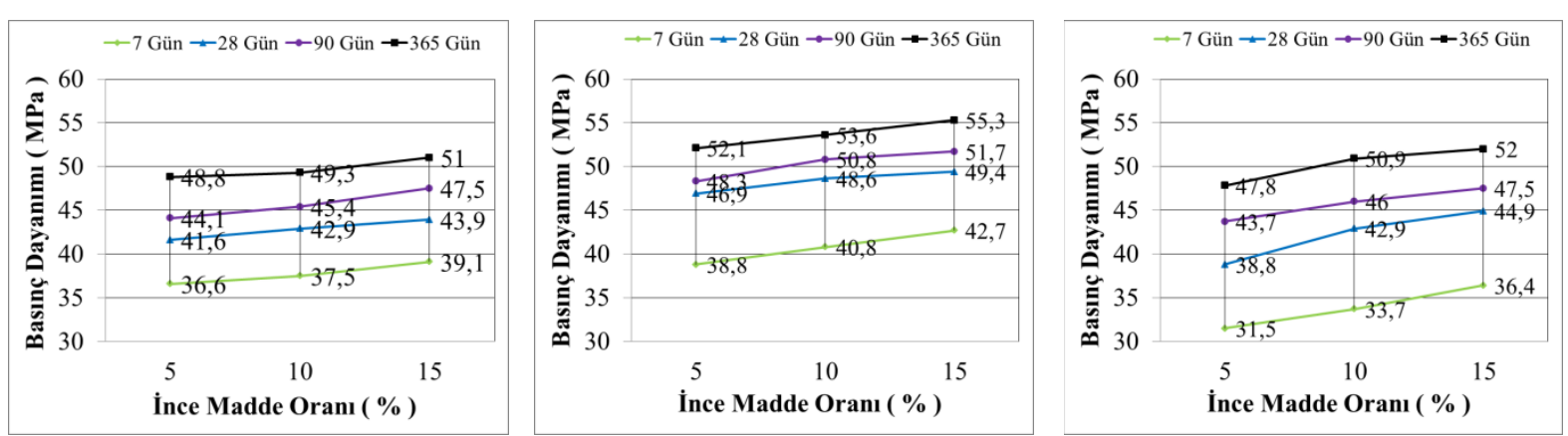

Şekil 12. 2.grup 1.takım, 2. takım ve 3. takım betonlardaki basınç dayanımı değişimleri 


\section{Sonuçlar}

$\mathrm{Bu}$ çalışmada aşağıda belirtilen sonuçlar tespit edilmiştir.

1. Kireçtaşı kökenli kırma kum agregalarında ince madde oranının \%15'e kadar bulunmas1 beton kıvam ve basınç dayanım özelliklerini olumsuz yönde etkilememektedir. Numunelere uygulanan 90 günlük ve 365 günlük beton basınç dayanımları bunun bir göstergesidir.

2. Kırma iri agrega ve kırma ince agrega ile üretilen aynı su/çimento oranına sahip kayma çökmeli betonla homojen çökmeli beton basınç dayanımları birbirine yakın değerler alabilmektedir. Slump deneyi sonucunda, kayma çökmesi görülen betonlarda kireç taş1 kökenli ince madde oranının artırılması sonucu hakiki çökmeli beton üretilebilmektedir.

3. İnce madde oranı arttıkça ince malzemeler iri malzemelerin arasinı doldurmakta ve böylelikle taze beton içerisindeki hava miktarı azalmaktadır.

4. Konkasörden gelen içerisinde $\% 15$ oranına kadar kireç kökenli ince madde muhtevasına sahip agreganın doğrudan betonda kullanılması eleme ve yıkama işlemi sonucunda ortaya çıkabilecek maliyetleri düşürmektedir.

\section{Teşekkür}

Yazarlar bu çalışmaya katkılarından dolayı DSİ Çoruh Projeleri 26. Bölge Müdürlüğü'ne teşekkür eder.

\section{Kaynaklar}

ASTM C 117, 2017. Standart test method for materials finer than $75-\mu \mathrm{m}$ (No.200) sieve in mineral aggregates by washing.

Benjeddou, O., Soussi, C., Jedidi, M. ve Benali, M., 2017. Experimental and theoretical study of the effect of the particle size of limestone fillers on the rheology of self-compacting concrete. Journal of Building Engineering, 10, 32-41.
Boğa, A.R., Kürklü, G. ve Ergün, A., 2014. Mermer tozu katkılı kendiliğinden yerleşen betonların taze ve mekanik özelliklerinin incelenmesi. ISEM2014, Adiyaman, 1239-1248.

Çobanoğlu, İ., Çelik, S.B., Çam, O., Etiz, H., Kurşun, M., 2014. Denizli bölgesi traverten atıklarının beton agregası olarak kullanılabilirliğinin incelenmesi. Pamukkale Üniversitesi Mühendislik Bilimleri Dergisi, 92-99.

Devlet Su İşleri Genel Müdürlüğü, 2006. Beton işleri teknik şartnamesi.

Gülan, L. ve Yıldız, S., 2016. Atık mermer tozu ve cam lif katk1l betonun mekanik ve fiziksel özellikleri üzerine karbonatlaşmanın etkisi. Fırat Üniversitesi Mühendislik Bilimleri Dergisi, 28, 189-200.

Laserna, S. ve Montero, J., 2016. Influence of natural aggregates typology on recycled concrete strength properties, Construction and Building Materials, 115, 78-86.

Özgan, E., 2005. Kırmataş agrega içerisindeki taş unu miktarının beton basınç dayanamına etkisi. Erciyes Üniversitesi Fen Bilimleri Enstitüsü Dergisi, 21, 198-205.

Ramyar, K., Çelik, T. ve Marar, K., 1995. Taş tozunun beton özelliklerine etkisi, endüstriyel atıkların inşaat sektöründe kullanılması. 2. Sempozyumu, Ankara, 227-237.

Rashad, A., 2016. Cementitious materials and agricultural wastes as natural fine aggregate replacement in conventional mortar and concrete. Journal of Building Engineering, 5, 119-141.

TS 706 EN 12620, 2009. Beton agregalar1, Türk Standardi.

TS EN 12350-7, 2010. Taze beton deneyleri, hava içeriğinin tayini, basınç metotları. Türk Standardi.

TS EN 206-1, 2014. Beton; özellik, performans, imalat ve uygunluk. Türk Standardi.

Uluöz, S., Yakıt, E. ve Düzbasan, S., 2004. Kırma agregadaki taş unu ve kil miktarının beton kalitesine etkisi. Beton 2004 Kongresi, İstanbul, 697-707. 